\title{
Development of SYBR Green I Based Real-Time RT-PCR Assay for Specific Detection of Watermelon silver mottle Virus
}

\author{
Xueqin Rao ${ }^{1,2, *}$, Jie Sun 1,2 \\ ${ }^{1}$ Department of Plant Pathology, College of Agriculture, South China Agricultural University, Guangzhou 510642, China \\ ${ }^{2}$ Guangdong Province Key Laboratory of Microbial Signals and Disease Control, South China Agricultural University, \\ Guangzhou 510642, China
}

${ }^{*}$ Corresponding author: Xue-qin Rao, Department of Plant Pathology, College of Agriculture, South China Agricultural University, Wushan Street, Tianhe District, Guangzhou 510642, China. Tel: +86-02085280306; Fax: +86-02085281107, E-mail: raoxq@hotmail.com

Received: January 09, 2015; Revised: March 16, 2015; Accepted: August 23, 2015

\begin{abstract}
Background: Watermelon silver mottle virus (WSMoV), which belongs to the genus Tospovirus, causes significant loss in Cucurbitaceae plants.

Objectives: Development of a highly sensitive and reliable detection method for WSMoV.

Materials and Methods: Recombinant plasmids for targeting the sequence of nucleocapsid protein gene of WSMoV were constructed. SYBR Green I real-time PCR was established and evaluated with standard recombinant plasmids and 27 watermelon samples showing WSMoV infection symptoms.

Results: The recombinant plasmid was used as template for SYBR Green I real-time PCR to generate standard and melting curves. Melting curve analysis indicated no primer-dimers and non-specific products in the assay. No cross-reaction was observed with Capsicum chlorosis virus (genus Tospovirus) and Cucumber mosaic virus (genus Cucumovirus). Repeatability tests indicated that inter-assay variability of the $C t$ values was $1.6 \%$.

Conclusions: A highly sensitive, reliable and rapid detection method of SYBR Green I real-time PCR for timely detection of WSMoV plants and vector thrips was established, which will facilitate disease forecast and control.

Keywords: Real-Time RT-PCR; SYBR Green I; Watermelon silver mottle virus
\end{abstract}

\section{Background}

Tospoviruses cause significant reductions in many important agricultural crops worldwide (1). These viruses belong to the family Bunyaviridae. Several tospoviruses have been reported in China (2-4) including but not limited to Watermelon silver mottle virus (WSMoV) that infects watermelons in South China (3), Japan (5) and Taiwan (6). WSMoV is an enveloped and single-stranded RNA virus that is persistently transmitted by thrips (7). The genome arrangement of the WSMoV is similar to that of other members of the genus Tospovirus (4). The viral RNA genome encloses large (L), medium (M), and small (S) RNA segments that encode different proteins (8). The L segment encodes RNA-dependent RNA polymerase (9). The $M$ segment encodes glycoproteins $(\mathrm{Gn} / \mathrm{Gc})$ and a nonstructural protein (NSm) (10). The S segment encodes nucleocapsid $(\mathrm{N})$ protein and another nonstructural protein (NSs) (11).

Diagnosis of WSMoV infections is important for controlling the spread of the watermelon silver mottle diseases. Current detection methods of WSMoV are electron microscopy (12), reverse transcriptase polymerase chain reaction (RT-PCR) (13), enzyme-linked immunosorbent assay (ELISA) (14), and RT-PCRELISA (15). However, these methods are time consuming, somewhat inaccurate and not quantitative. On the other hand, real-time quantitative PCR promises faster results with greater sensitivity and specificity (16). WSMoV diagnosis can be improved remarkably using real-time PCR.

Real-time quantitative PCR technology has been successfully applied for detection of various plant viruses, such as grapevine viruses (17), Tomato yellow leaf curl virus (18), Wheat dwarf virus (19), Citrus tristeza virus (20), and Tomato spotted wilt virus (21). SYBR Green I amongst varieties of suggested probes that can be used in Real-Time PCR have found its place as the commonly used probe. Simplicity of primer design, lower test cost and ease of use with 
minor pipetting errors and cross-contamination are some of the reasons for the preference of SYBR Green I application in molecular-related techniques (22).

\section{Objectives}

In this study, SYBR Green I real-time RT-PCR assay targeting the N protein gene of S RNA for detection of WSMoV was developed. This assay will improve efficiency and sensitivity of the diagnosis.

\section{Materials and Methods}

\subsection{Primer Design}

A specific primer pair was designed based on the nucleocapsid $(\mathrm{N})$ protein gene of WSMoV published previously in GenBank (accession no. HQ695853). The forward and reverse primer sequences were F1 (5'-CTTATGGGTTGAATGTGCCTG-3': the position of WSMoV N protein gene of 395 to 415$)$ and R1 (5'CCTTAGCCACTTTACAAACTTG-3' ${ }^{\prime}$ : the position of WSMoV N protein gene of 577 to 598), respectively. The primers were synthesized by TaKaRa (Dalian, China).

\subsection{RNA Extraction and cDNA Synthesis}

Infected watermelons with signs of disease symptoms of WSMoV were collected from Guangzhou, South China and the infection was confirmed by double antibody sandwich ELISA (DAS-ELISA) and RTPCR as described previously (3). Total RNA was extracted using RNA Extraction kit (May Gene, China) according to the manufacturer's protocol. The extracted RNA was dissolved in DEPC-treated $\mathrm{ddH}_{2} \mathrm{O}$, and stored at $-20^{\circ} \mathrm{C}$ until further use. The cDNA was synthesized from total RNA isolated from infected watermelon leaves using PrimeScript ${ }^{\mathrm{TM}}$ RT Master Mix kit (TaKaRa, Dalian, China) following the manufacturer's instructions. The reaction conditions were: $37^{\circ} \mathrm{C}$ for $15 \mathrm{~min}, 85^{\circ} \mathrm{C}$ for $5 \mathrm{~s}$. The synthesized cDNA was stored at $-20^{\circ} \mathrm{C}$.

\subsection{Construction of Standard Curve}

In order to construct the standard curve, one-step RT-PCR was performed with the WSMoV specific primer pair F1/R1. The amplification was carried out in a reaction volume of $25 \mu \mathrm{L}$ by using TaKaRa OneStep RT-PCR kit (Dalian, China) with $1 \mu \mathrm{M}$ of forward and reverse primers (F1/R1). The reaction conditions were set at $50^{\circ} \mathrm{C}$ for $30 \mathrm{~min}$ and $94^{\circ} \mathrm{C}$ for $5 \mathrm{~min}$, followed by 35 cycles of $94^{\circ} \mathrm{C}$ for $30 \mathrm{~s}, 58^{\circ} \mathrm{C}$ for $30 \mathrm{~s}$ and $72^{\circ} \mathrm{C}$ for $1 \mathrm{~min}$, with a final extension step of $72^{\circ} \mathrm{C}$ for
$10 \mathrm{~min}$. The amplification product was analyzed by gel electrophoresis. A 204 bp DNA fragment of the N protein gene of WSMoV was amplified and cloned into a pMD18-T vector (TaKaRa, Dalian, China). The positive plasmids were confirmed by sequencing. The DNA concentration of the positive plasmid was determined by NanoPhotometer Pearl P300 (IMPLEN, Germany) and converted to molecular copies.

The plasmids were diluted 10 -fold serially to have final concentrations of $5.6 \times 10^{3-7}$ copies $/ \mu \mathrm{L}$. A standard DNA curve for the range of $5.6 \times 10^{7}$ to $5.6 \times 10^{3}$ DNA copies per reaction was generated by analyzing each dilution in triplicate by SYBR Green I real-time PCR. The standard curve was constructed by plotting a linear regression curve with the mean $C t$ values on the $\mathrm{Y}$-axis and the copy number on the $\mathrm{X}$-axis.

\subsection{SYBR Green I Real-Time RT-PCR Assay and Melting Curve}

The SYBR Green I based real-time RT-PCR assay was performed using a SYBR PrimeScript RT-PCR Kit (TaKaRa, Dalian, China) according to the instructions in Thermal Cycler Dice Real Time System TP800 (TaKaRa, Dalian, China). The $25 \mu \mathrm{L}$ reaction contained $2 \mu \mathrm{L}$ DNA template, $0.4 \mathrm{mM}$ each of F1 and R1 primers, 12.5 L SYBR Premix Ex Taq, $8.5 \mu \mathrm{L}$ $\mathrm{ddH}_{2} \mathrm{O}$. Cycling conditions included $30 \mathrm{~s}$ of denaturation at $95^{\circ} \mathrm{C}$, followed by 40 cycles of PCR amplification at $95^{\circ} \mathrm{C}$ for $5 \mathrm{~s}, 58^{\circ} \mathrm{C}$ for $30 \mathrm{~s}$. A melting curve was recorded by holding at $95^{\circ} \mathrm{C}$ for $15 \mathrm{~s}$, cooling to $60^{\circ} \mathrm{C}$ for $30 \mathrm{~s}$, and heating at $95^{\circ} \mathrm{C}$ for $15 \mathrm{~s}$. The melting curve was performed using dilutions of $5.6 \times 10^{7}$ to $5.6 \times 10^{3}$ of the plasmid DNA. Each concentration of the plasmid DNA was checked twice. The amplification and melting curve data were collected and analyzed using the Thermal Cycler Dice Real Time System TP800 software (TaKaRa, Dalian, China).

\subsection{Assay Specificity}

The specificity of WSMoV SYBR Green I realtime PCR was assessed by testing the cDNAs generated from Capsicum chlorosis virus $(\mathrm{CaCV}$, genus Tospovirus), WSMoV, Cucumber mosaic virus (CMV, genus Cucumovirus) isolates, and the healthy watermelon leaf. The real-time PCR products were also verified by electrophoresis on a $2 \%(\mathrm{w} / \mathrm{v})$ agarose gel.

\subsection{Assay Reproducibility}

To assess the reproducibility of the real-time RTPCR, the inter-assay variability of the $C t$ values obtained after amplification of $5.6 \times 10^{6}$ copies per 
reaction of the plasmid DNA standard was checked eight times.

\subsection{Evaluation of the SYBR Green I Real-Time RT- PCR Assay}

Twenty seven watermelon samples with signs of WSMoV-like infection symptoms collected from Guangzhou, China were evaluated by SYBR Green I real-time RT-PCR assay to confirm the feasibility of this technique in detection of the foreign viral particles. At the same time, all samples were detected with RT- PCR. Samples with $C t$ values exceeding 35 cycles were regarded as negative.

\section{Results}

\subsection{Construction of Recombinant Plasmids}

A 204 bp target fragment was amplified by RT-PCR and cloned in a pMD18-T vector. The pMD18-T recombinant clones were analyzed and sequenced. The results indicated that the sequences were completely consistent with the $\mathrm{N}$ protein gene target of WSMoV (4).

\subsection{Standard Curve}

A standard curve was determined by using 10fold serial dilutions of the DNA standards ranging from $5.6 \times 10^{7}$ to $5.6 \times 10^{3}$ copies/reaction in triplicate (Figure 1). Ct-values were measured and plotted against the known copy numbers of the standard sample. The standard curve covered a linear range of five orders of magnitude. The standard curve of WSMoV

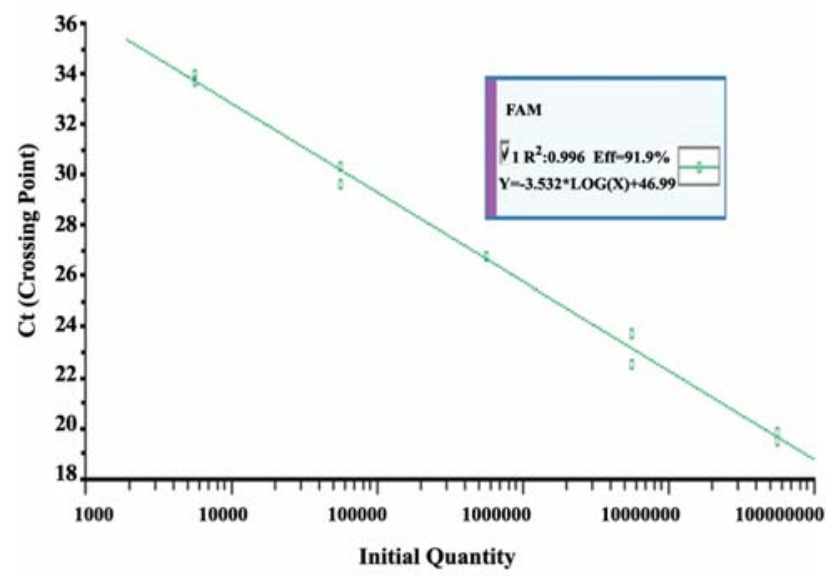

Figure 1. Standard curve showing a linear relationship between standard DNA concentrations and $C t$ values for WSMoV. A linear regression curve was generated by plotting the $C t$ values on the $\mathrm{Y}$ axis vs. the initial quantity (number of copies of the plasmid DNA) on X-axis. The experiment was performed in triplicate. The equation of the straight line and the coefficient of correlation $\left(R^{2}\right)$ are represented on the graph showed the equation of $y=-3.532 \operatorname{LOG}(X)+46.99$ and coefficient of correlation $\left(R^{2}\right)$ of 0.996 (Figure 1). The standard curve showed an amplification efficiency of $91.9 \%$ and covered a linear range from $5.6 \times 10^{7}$ to $5.6 \times 10^{3}$ copies of viral cDNA. This assay could also be used to quantify target RNA in infected tissue.

\subsection{Melting Curve}

To verify the correct product, melting curve analysis was performed using different concentrations of the plasmid DNA. The melting curve showed that the WSMoV N protein gene-specific amplicon melts at $81^{\circ} \mathrm{C}$ (Figure 2), and no primer-dimers were detected. All reactions with WSMoV target genes were present exhibited a single dissociation peak. No dissociation curve was reported for cDNA from the uninfected watermelon leaf for any reactions.

\subsection{Specificity of SYBR Green I Based Real-Time RT- PCR}

The real-time RT-PCR assay in this study was specific for WSMoV. The specific amplifications were also confirmed by detecting specific bands of $204 \mathrm{bp}$ for WSMoV using agarose gel electrophoresis. No specific products were detected for $\mathrm{CaCV}$ and $\mathrm{CMV}$ isolates, and the healthy watermelon leaf (Figure 3).

\subsection{Reproducibility of the Real-Time RT-PCR}

Standard plasmid with $5.6 \times 10^{6}$ copies per reaction were subjected to SYBR Green I real-time PCR. The results were consistent in all 8 times that we were repeated the experiment (Figure 4). The means of interassay variability of the $C t$ values obtained for the DNA

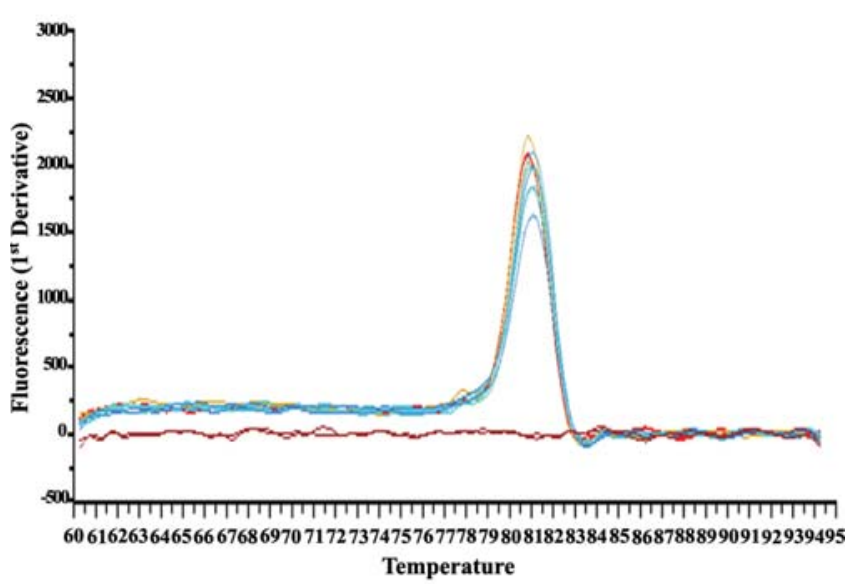

Figure 2. Melting curve analysis of the SYBR Green I based realtime PCR products for WSMoV, which obtained with dilutions of $5.6 \times 10^{7}$ to $5.6 \times 10^{3}$ of the plasmid DNA. Each concentration of the plasmid DNA was performed two times 


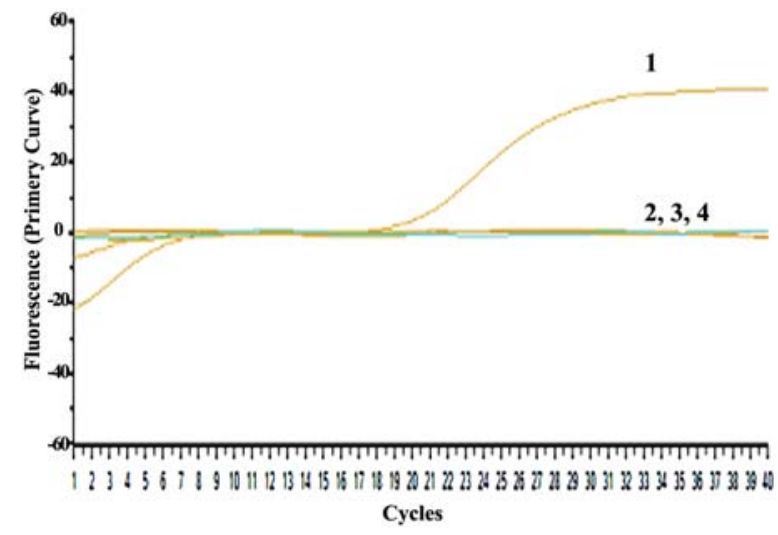

Figure 3. The specificity of the SYBR Green I real time RT-PCR assay of detection of WSMoV, CaCV, and CMV infected samples. Lane 1: the cDNAs generated from WSMoV isolate. Lanes 2-3: the cDNAs generated from $\mathrm{CaCV}$ and $\mathrm{CMV}$ isolates, respectively. Lane 4: the cDNAs generated from total RNA of healthy watermelon leaves

standard curve were $1.6 \%$. These results suggest that real-time PCR has good reproducibility of inter-assays.

\subsection{Evaluation of Assay Performance}

To evaluate the performance of SYBR Green I assay for detection of WSMoV, 27 watermelon samples showing WSMoV infection-like symptoms were analyzed. $C t$ values of 19 samples were less than 35 cycles (data not shown). The results showed that 19 out of the 27 samples were positively confirmed by SYBR Green I assay. Among them, 18 positive samples of real-time RT-PCR were detected to be positive through RT-PCR (data not shown). The agreement for WSMoV between SYBR Green I real-time RT-PCR and the conventional RT-PCR was $94.7 \%$.

\section{Discussion}

In South China, high temperature and high cropping index are favorable for the WSMoV disease development and thrips outbreak, which results in significant yield reductions. Although several techniques have been developed for WSMoV detection, more sensitive SYBR Green I real-time RT-PCR assay will produce more accurate detection result. The present study describes a SYBR Green I real-time RT-PCR assay for routine laboratory diagnosis of WSMoV infection.

SYBR Green I real-time PCR assay is ideal for using a DNA-binding dye because such dyes are inexpensive. Given the high sensitivity of SYBR Green I real-time PCR, many factors affect the accuracy of the assay. The major disadvantage of SYBR Green I realtime PCR assay occurs when the dye molecules bind to

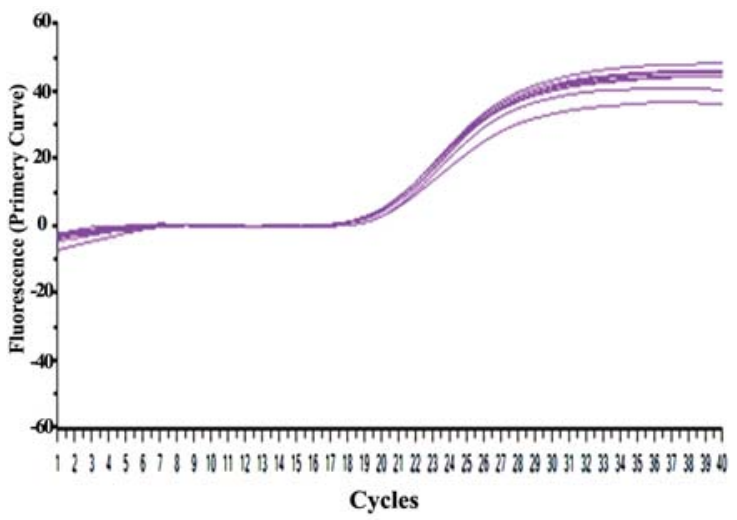

Figure 4. Reproducibility analysis of the specificity of the SYBR Green I based real-time PCR assay by evaluating the mean variability obtained after amplification of $5.6 \times 10^{6}$ copies per reaction in eight times

double-stranded DNA fragments in the reaction, including primer-dimers and non-specific products. Therefore, melting curve analysis following real-time $\mathrm{PCR}$ is required to guarantee reaction accuracy. The established real-time RT-PCR assay in this study showed good specificity, in which only one sharp peak was detected in the melting curve chart (Figure 2), suggesting the absence of primer-dimers and non-specific products in the reaction. The specificity was also verified through agarose gel electrophoresis.

To generate the standard curve of WSMoV, a plasmid DNA representing the partial $\mathrm{N}$ protein gene of WSMoV was used as the template, which made the procedure very quick and simple (23). The wide linear range of 5 to 7 units covered by the standard curves was similar to that of other reported SYBR Green I assays for virus detection $(18,23) . R^{2}$ value was 0.996 , which indicated good correlation between viral copy numbers and $C t$ values. The amplification efficiency was $91.9 \%$, which is well within the permissible range ( $90 \%$ to $120 \%$ ), indicating highly efficient amplification. About $1.6 \%$ of the mean inter-assay variability of the $C t$ values was considered acceptable for SYBR Green I real-time PCR assay (24).

The agreement between the SYBR Green I realtime RT-PCR and the conventional RT-PCR was more than $90 \%$. The results showed that the sensitivity of SYBR Green I real-time RT-PCR was higher than that of conventional RT-PCR, which is less sensitive than those reported for other viruses $(23,25)$. This finding may be attributed to the efficiency of reverse transcription reaction, PCR cycling conditions, and perform- 
ance of real-time PCR instruments, including the concentration of viruses in plants.

In this study, a highly sensitive and efficient SYBR Green I real-time RT-PCR method for the detection of WSMoV in infected samples was developed and proven useful for WSMoV detection and field investigation.

\section{References}

1. Pappu HR, Jones RAC, Jain RK. Global status of tospovirus epidemics in diverse cropping systems: Successes achieved and challenges ahead. Virus Research. 2009;141(2):219-236. DOI: 10.1016/j.virusres.2009.01.009.

2. Dong JH, Yin YY, Fang Q, Mcbeath JH, Zhang ZK. A new tospovirus causing chlorotic ringspot on Hippeastrum sp. in China. Virus Genes. 2013;46(3):567-570. DOI: 10.1007/ s11262-012-0873-Z.

3. Rao X, Liu Y, Wu Z, Li Y. First report of natural infection of watermelon by Watermelon silver mottle virus in China. New Disease Reports. 2011;24:12. DOI: 10.5197/j.2044-0588.2011.0 24.012.

4. Rao X, Wu Z, Li Y. Complete genome sequence of a Watermelon silver mottle virus isolate from China. Virus Genes. 2013;46(3):576-580. DOI: 10.1007/s11262-013-0885-3.

5. Iwaki M, Honda Y, Hanada K, Tochihara H. Silver mottle disease of watermelon caused by tomato spotted wilt virus. Plant Dis. 1984;68(11):1006-1008. DOI: 10.1094/PD-68-1006.

6. Yeh SD, Chang TF. Nucleotide sequence of the $\mathrm{N}$ gene of Watermelon silver mottle virus, a proposed new member of the genus Tospovirus. Phytopathology. 1995;85(1):58-64. DOI: 10.1094/Phyto-85-58.

7. Peng JC, Yeh SD, Huang LH, Li JT, Cheng YF, Chen TC. Emerging threat of thrips-borne Melon yellow spot virus on melon and watermelon in Taiwan. Eur J Plant Pathol. 2011;130(2):205-214. DOI: 10.1007/s106 58-011-9746-x.

8. Adkins S. Tomato spotted wilt virus - positive steps towards negative success. Mol Plant Pathol. 2000;1(3):151-157. DOI: 10.1046/j.1364-3703. 2000.00022.x.

9. de Hann P, Kormelink R, de Oliveira Resende R, van Poelwijk F, Peters D, Goldbach R. Tomato spotted wilt virus L RNA encodes a putative RNA polymerase. J Gen Virol.1991;72 (pt9):2207-2216. DOI: 10.1099/0022-1317 -72-9-2207.

10. Kormelink R, Storms M, Van Lent J, Peters D, Goldbach R. Expression and subcellular location of the NSM protein of Tomato spotted wilt virus (TSWV), a putative viral movement protein. Virology. 1994;200(1):56-65. DOI: 10. 1006/viro.19 94.1162.

11. Sin SH, McNulty BC, Kennedy GG, Moyer JW. Viral genetic determinants for thrips transmission of Tomato spotted wilt virus. Proc Natl Acad Sci USA. 2005;102(14):5168-5173. DOI: $10.1073 /$ pnas.0407354102.

12. Yeh SD, Lin YC, Cheng YH, Jih CL, Chen MJ, Chen CC. Identification of tomato spotted wilt-like virus on watermelon in Taiwan. Plant Dis. 1992;76(8):835-840. DOI: 10.1094/PD76-0835.

13. Uga H, Tsuda S. A one-step reverse transcription-polymerase chain reaction system for the simultaneous detection and identification of multiple tospovirus infections. Phytopathology
2005;95(2):166-171. DOI: 10.1094/PHY TO-95-0166.

14. Wu Z, Wang W, Li Y, Rao X. Development of polyclonal anti bodies against nucleocapsid protein of watermelon silver mottle virus and their application to diagnostic. Acta Virologica. 2014;58(2):167-172. DOI: 10.4149/av_2014_02_167.

15. Charoenvilaisiri S, Seepiban C, Bhunchoth A, Warin N, Luxananil P, Gajanandana O. Development of a multiplex RTPCR-ELISA to identify four distinct species of tospovirus. $J$ Virol Methods. 2014;202(7):54-63. DOI: 10.1016/j.jviromet. 2014.03.003.

16. Dash PK, Boutonnier A, Prina E, Sharma S, Reiter P. Development of a SYBR green I based RT-PCR assay for yellow fever virus: application in assessment of YFV infection in Aedes aegypti. Virol J. 2012;9(3):400-402. DOI: 10.1186/17 43-422X-9-27.

17. López-Fabuel I, Wetzel T, Bertolini E, Bassler A, Vidal E, Torres LB, Yuste A, Olmos A. Real-time multiplex RT-PCR for the simultaneous detection of the five main grapevine viruses.J Virol Methods. 2012;188(1-2):21-24. DOI: 10.1016/ j.jviromet.2012.11.034.

18. Mason G, Caciagli P, Accotto GP, Noris E. Real-time PCR for the quantitation of Tomato yellow leaf curl Sardinia virus in tomato plants and in Bemisia tabaci. J Virol Methods. 2008;147(2):282-289. DOI: 10.1016/j.jviromet.2007.09.015.

19. Zhang X, Zhou G, Wang X. Detection of Wheat dwarf virus (WDV) in wheat and vector leafhopper (Psammotettix alienus Dahlb.) by real-time PCR. J Virol Methods. 2010;169(2):416419. DOI: 10.1016/j.jviromet.2010.07.029.

20. Ruiz-Ruiz S, Moreno PJ, Ambros S. A real-time RT-PCR assay for detection and absolute quantitation of Citrus tristeza virus in different plant tissues. J Virol Methods. 2007;145(2):96-105. DOI: 10.1016/j.jviromet.2007.05.011.

21. Debreczeni DE, Ruiz-Ruiz S, Aramburu J, López C, Belliure B, Galipienso L, Soler S, Rubio L. Detection, discrimination and absolute quantitation of Tomato spotted wilt virus isolates using real time RT-PCR with TaqMan(®)MGB probes. J Virol Methods. 2011;176(1-2):32-37. DOI: 10.1016/j.jviromet. 2011.05.027.

22. Ogawa H, Taira O, Hirai T, Takeuchi H, Nagao A, Ishikawa Y, Tuchiya K, Nunoya T, Ueda S. Multiplex PCR and multiplex RT-PCR for inclusive detection of major swine DNA and RNA viruses in pigs with multiple infections. J Virol Methods. 2009;160(1-2):210-214. DOI: 10.1016/j.jviromet.2009. 05.010.

23. Shweta S, Indranil D. Development of SYBR Green I based real-time PCR assays for quantitative detection of Rice tungro bacilliform virus and Rice tungro spherical virus. J Virol Methods. 2012;181(1):86-92. DOI: 10.1016/j.jviromet.2012. 01.018.

24. Islam A, Harrison B, Cheetham BF, Mahony TJ, Young PL, Walkden-Brown SW. Differential amplification and quantitation of Marek's disease viruses using real-time polymerase chain reaction. J Virol Methods. 2004;119(2):103-113. DOI: 10.1016/j.jviromet.2004.03.006.

25. Ruiz-Ruiz S, Ambrós S, Vives MDC, Navarro L, Moreno P, Guerri J. Detection and quantitation of Citrus leaf blotch virus by TaqMan real-time RT-PCR. J Virol Methods. 2009;160(12):57-62. DOI: 10.1016/j.jviromet.2009.04.012. 